University of Nebraska - Lincoln

DigitalCommons@University of Nebraska - Lincoln

Sociology Department, Faculty Publications

Sociology, Department of

4-7-1973

\title{
The Culture of Poverty Debate: Some Additional Data
}

Barbara E. Coward

Houston Community College System

Joe R. Feagin

University of Texas at Austin, feagin@tamu.edu

J. Allen Williams Jr.

University of Nebraska-Lincoln, jwilliams2@unl.edu

Follow this and additional works at: https://digitalcommons.unl.edu/sociologyfacpub

Part of the Sociology Commons

Coward, Barbara E.; Feagin, Joe R.; and Williams, J. Allen Jr., "The Culture of Poverty Debate: Some Additional Data" (1973). Sociology Department, Faculty Publications. 4.

https://digitalcommons.unl.edu/sociologyfacpub/4

This Article is brought to you for free and open access by the Sociology, Department of at DigitalCommons@University of Nebraska - Lincoln. It has been accepted for inclusion in Sociology Department, Faculty Publications by an authorized administrator of DigitalCommons@University of Nebraska - Lincoln. 
Published in Social Problems 21 (1973), pp. 621-634.

Copyright (C) 1973 by the Society for the Study of Social Problems, Inc. Published by the University of

California Press. Used by permission. http://www.ucpressjournals.com/journal.asp?j=sp

The data reported in this paper were collected as part of a larger study supported by the Department of Housing and Urban Development and prepared for the Urban Renewal Agency of the City of Austin, Texas. The authors are indebted to Louis A. Zurcher for his comments on an earlier version of this paper.

\title{
The Culture of Poverty Debate: Some Additional Data
}

\author{
Barbara E. Coward, Houston Community College System \\ Joe R. Feagin, University of Texas at Austin \\ J. Allen Williams, Jr., University of Nebraska-Lincoln
}

\begin{abstract}
In this paper we briefly review relevant research on the culture of poverty and set our findings within the general context of culture of poverty arguments. Data from a community survey in a Southwestern city are analyzed using Oscar Lewis' four major culture of poverty dimensions: 1) the individual, 2) the family, 3) the slum community, and 4) the community's relation to society. In our study a sample of 271 black respondents was divided into two groups, here termed the "poor" and the "non-poor." In noting all the broad traits studied in all dimensions taken together, some support for Lewis' culture of poverty was found in less than half of the cases; and in several cases our findings were in direct opposition to culture of poverty predictions. In addition, we have suggested that the majority of those traits that did lend support to Lewis' argument might be better classified as situational conditions of poverty rather than as a part of a bona fide "culture" of poverty. The findings of this paper may call into question the use of the "culture of poverty" perspective as a basis for policy decisions.
\end{abstract}

The phrase "culture of poverty" and the perspective on the poor it denotes have become common in the growing literature on the poor. While criticism of this perspective, originally developed in the 1950's by Oscar Lewis, has become more frequent in recent years, surprisingly little empirical research has examined the generalizations about poverty asserted by Lewis and his followers. The purpose of this paper is (1) to review briefly the state of comparative empirical research on the culture of poverty and then (2) to ex- 
amine the extent to which our findings, based on a re-analysis of a community survey, lend support to poverty culture arguments.

Let us briefly review the culture of poverty perspective. At one point Lewis (1964:149) tells us his purpose is to form a "conceptual model ... in terms of a configuration of a large number of interrelated traits of which poverty is the crucial one." Critical to his view too is the definition of a poverty culture as a "design for living which is passed down from generation to generation" (Lewis, 1964:150). But perhaps the best explanation is this:

... it has a structure, a rationale, and defense mechanisms without which the poor could hardly carry on. In short, it is a way of life, remarkably stable and persistent, passed down from generation to generation along family lines. The culture of poverty has its own modalities and distinctive social and psychological consequences for its members. It is a dynamic factor which affects participation in the large national culture and becomes a subculture of its own (Lewis, 1964: 150).

Illustrating this structure and rationale, Lewis (1965) prepared a catalogue of 70 traits which characterize a poverty culture. ${ }^{1}$ Among these diverse traits are such things as a provincial perspective, unemployment, absence of savings, lack of privacy, gregariousness, frequent use of physical violence in child training, predisposition to authoritarianism, inability to defer gratification, fatalism, mistrust of government, and strong feelings of powerlessness, marginality, and helplessness.

Further, Lewis (1965:xiv) grouped his list of 70 odd traits into four basic categories or points of view from which one can analyze those in a poverty culture. In the order we will consider them subsequently, these categories are:

(1) the attitudes, values, and character structure of the individual;

(2) the nature of the family;

(3) the nature of the slum community;

(4) the relationship between the culture and the larger society.

That this perspective on poverty has spread rapidly among social scientists and policy makers can easily be demonstrated by reference to the burgeoning literature on poverty of the 1960's and 1970's. Indeed, examination of major government publications on poverty might lead one to the view that the federal government has played an important role in legitimizing and popularizing the culture of poverty perspective. For example, in an important summary volume for practitioners and researchers, Growing $U_{p}$ Poor, Chilman (1966) lists numerous family, lifestyle, and attitudinal traits of the very poor in a fashion similar to Oscar Lewis, and then links policy-oriented solutions to these traits. Considering these traits as barriers to the adaptation of the poor in American society, she (Chilman, 1966:75) concludes on a public policy note:

From the available evidence, it seems clear that changes in subcultural patterns of a number of very poor people are probably indicated as one of a number of measures designed to facilitate upward mobility for themselves and their children. Unfortunately, planned changes in culture patterns are extremely difficult to effect.

While Chilman's conclusions are cautiously worded, those of other writers and numerous policy makers have been less so, resulting in a heavy emphasis in some cir-

\footnotetext{
${ }^{1} \mathrm{~A}$ listing of these traits and a more complete analysis of the theoretical problems surrounding the culture of poverty can be found in Holland (1971).
} 
cles on remedial strategies focusing on eradicating pathological cultural traits assumed to be typical among the very poor. Such discussions indicate that the culture of poverty issue is not just an abstract theory to be analyzed in the private places of social scientists, but a critical notion with serious policy implications.

\section{Research and Analysis on the Culture of Poverty}

While a number of critiques of the culture of poverty perspective have appeared in recent years, including those by Rodman (1964), Valentine (1971), Roach and Gursslin (1967), and Leeds (1971), few social science researchers have attempted to examine the applicability of Lewis' arguments to groups of the poor and the non-poor, for more than one aspect of one of the dimensions at a time. Indeed, in his provocative analysis Valentine has suggested that one of the most serious defects in current studies of the poor is the lack of comparative and across-the-board analysis of this type. A major task of research on the poor, he argues (1968: 114-115), should be "to discern what cultural features are shared by different but related subsystems" and "what culture traits or configurations are shared by the lower class with the middle class or with the system as a whole."

As for empirical studies of poverty culture life styles, one is hard pressed to find studies which (1) explicitly attempt to test Lewis' generalizations for groups of the poor and non-poor and (2) examine traits from more than one aspect of one of Lewis' four basic dimensions of poverty culture in the same research study (an enterprise necessary, it would seem, to get at the question of an integrated culture). While a number of articles have dealt with one or two traits assumed to be characteristic of the poor, such as the inability to postpone gratification, we have been able to find only three studies that have made any attempt to compare two different socioeconomic groups, one poor and one not-so-poor, in regard to a number of different traits.

One such study was by Schneiderman (1964), who reported on a research effort that tested whether persons who were chronically impoverished did in fact have a different life style from those more affluent. He compared 35 chronic welfare assistance families with two somewhat larger samples of the nonpoor. Using the five basic Kluckhohn-Strodtbeck value orientation measures, Schneiderman found that these very poor respondents differed from the more affluent comparison samples on three of the five major value orientation dimensions. The groups did not differ significantly in their values with regard to the character of human nature or with regard to the nature of man's relation to other men. They did differ significantly in regard to views of nature ("subject to" versus "mastery over"), to views on modes of human activity ("being" versus "doing"), and to views of time ("present" versus "future"). Schneiderman concludes that the impoverished man shares a common life-style or design for living that is internally consistent and distinctive from that dominant in the general community. In line with other culture of poverty theorists, he takes the position that one consequence of prolonged poverty is the production of a distinctive culture shared by the very poor and transmitted from one generation to the next through each family's socialization practices. While Schneiderman is one of the few who has examined a number of different traits, still one might question whether his sweeping generalizations are possible on the basis of a small and select group of the poor 
(chronic welfare recipients), particularly since these respondents cannot be considered representative of the very poor, most of whom are not on welfare.

A second study by Johnson and Sanday (1971) was focused primarily on subcultural variations among ethnic groups. In addition, these researchers did examine differences between socioeconomic subgroups, the poor and the non-poor, in a sample of heads of low-income and moderate-income households in three Pittsburgh neigborhoods. Their findings did not consistently support a culture of poverty interpretation. With regard to family structure (one of Lewis' family character traits), Johnson and Sanday found a statistically significant tendency for the poor to have more female-headed families than the non-poor. However, on their measure of future orientation (one of Lewis' attitudinal traits) - and in contrast to Schneiderman-they found no significant difference between the poor and the non-poor. Questions which might be considered crude indexes of two other culture of poverty traits, the achievement ethic and the trust-in-people trait, also did not reveal statistically significant differences between the poor and the non-poor.

Although the major focus was not on differences between the poor and the nonpoor, but rather on ethnic variation in culture of poverty perspectives among the poor, a study by Irelan, Moles, and O'Shea (1969) does raise some serious questions about the general applicability of culture of poverty arguments across all racial and ethnic groups. Contrary to what one might predict from the Lewis perspective, Irelan, Moles, and O'Shea found that there was considerable and statistically significant variation among poor samples from three ethnic groups (Anglo, Chicano, and black) in agreement with questions which tap culture of poverty traits. Although these data could have been analyzed further, focusing on variation by socioeconomic status, no such analysis is provided. Inspection of their data on two traits, alienation and fatalism, however, does indicate weak directional support for the view that the very poor among these poor respondents were somewhat more alienated and fatalistic than the rest. Thus, our review of empirical research looking at a number of aspects of the culture of poverty did not turn up evidence of a quality or quantity to lend substantial or unequivocal support for Lewis' arguments, at least as they might be applied to the poor in the United States.

\section{Method}

With this backdrop of limited empirical research in mind, we used data from a community survey that would allow us to compare groups of the poor and the non-poor within one specific ethnic group in the United States. Interviews were conducted with members of households in a black neighborhood designated for urban renewal in a large Southwestern city. ${ }^{2}$ A random sample of 100 households was drawn from the entire ghetto area and no significant socioeconomic differences were found between this sample and the neighborhood sample. The total sample utilized here consists of those 271 black households on which adequate income data

\footnotetext{
${ }^{2}$ The total sample consists of 321 black households in one neighborhood of this southwestern city-97 percent of all the households in the area. Attempts to assure response validity included pretesting the schedule, intensive interviewer training (often lasting for several weeks), using only black interviewers, call-backs when information was not clear, duplicate interviews on selected households, and separate interviews with two adult members of selected households to compare responses.
} 
were available, a sample which we further divided for the purposes of this analysis into two income groups: a very low-income group (the "poor") and a moderate-income group (the "non-poor"). This procedure seemed reasonable for two reasons. First, Oscar Lewis himself has noted that very low-income black Americans are particularly likely to be characterized by the culture of poverty traits and further has suggested that those blacks somewhat better off are probably not accurately characterized in such terms. We have sorted out the very low income group in our sample to compare with those who are somewhat better off. Secondly, two research studies which we have cited previously (Irelan, Moles, and O'Shea, 1969; Johnson and Sanday, 1971) have indicated that major problems are introduced into analysis of culture of poverty hypotheses when the poor and nonpoor groups analyzed are actually comprised of a number of different ethnic groups. For this reason, we would urge future analyses of poverty culture arguments to focus on differences by socioeconomic status within racial or ethnic groups, or in a larger analysis to control for race and ethnicity. Given the data available, we have chosen the former procedure-an analysis of income groups within a black sample.

The division into two groups, the "poor" and the "non-poor," was in terms of total annual income before taxes for all household members. The income figure was adjusted for size of family, roughly following the rather conservative poverty line utilized by the U.S. Census Bureau. Based on this, 132 of our respondents were classified as "poor," the rest ( $\mathrm{N}=139$ ) as "non-poor." As expected, the poor sample had a substantially lower edu- cation median. Since our total sample's overall median age was somewhat higher than that for all black adults in the city, we have controlled for age in examining the relationships between income and culture of poverty traits.

In our analysis we have grouped the relevant questions in the comprehensive survey instrument into the four basic poverty culture dimensions. Although we could not examine all 70 traits delineated by Lewis, we have been unusually fortunate in having some indicators relevant to each of the four major dimensions. Questions have been cross-tabulated by income, the independent variable, with one important category for each cross-tabulation reported in our summary tables. Chi-square statistics were calculated and tested for significance. We realize the "as if" character of reporting significance levels for a sample which is not a strictly random sample, but rather a population. We are here following the line of reasoning developed by the statisticians $\mathrm{Ha}^{-}$ good and Price (1952:286-294), who have suggested that in the present state of social science research statistical criteria of significance can reasonably be used as a heuristic standard for evaluating objectively relationships in observed samples.

\section{Dimension I: Attitudes, Values, and Character Structure of the Individual}

Perhaps the most important, and widely discussed, poverty culture traits fall under the dimension Lewis terms the "attitudes, values and character structure of the individual." These basic attitudes and val-

${ }^{3}$ Since the median income for the "non-poor" group is $\$ 4680$ for families averaging about 2-3 persons, compared to a median of $\$ 1680$ for the "poor" group, we would like to underline the fact that the term "non-poor" is here used in a relative, not an absolute, sense. Certainly, the modest per capita incomes of the "non-poor" do not qualify them for the label "affluent." 
ues, chief among which are such orientations as alienation and powerlessness, have become central to discussions of a culture of poverty transmitted across generations. Since these traits can easily be discussed in cultural terms, and are the least likely to be problematical-that is, the least likely to be viewed alternatively as "externally imposed conditions or unavoidable matters of situational expediency" (Valentine, 1968:115)demonstration of their distinctive presence among the very poor seems critical for culture of poverty theories.

What did the survey data reveal in this regard? Our data (Table 1) generally do not support arguments for the distinctiveness of the very poor with regard to the traits falling under this dimension. Included in the survey instrument were the subscales of powerlessness, normlessness, and social isolation, component parts of Dean's (1961) alienation scale. We found no statistically significant relationship between income and powerlessness, and the direction of the relationship is opposite the direction predicted by poverty culture theorists. In the case of the normlessness scale, we did find a significant relationship; but in this case too the relationship was opposite that predicted. The poor were less likely to rank high on this scale than the non-poor. However, the cross-tabulation on the social isolation scale and income shows a significant relationship in the direction predicted by poverty culture theories. Thus, the three measures of different aspects of alienation each revealed a different pattern, with support for the culture of poverty perspective in only one of the three cross-tabulations.

The measure of self-esteem, drawn from Rosenberg's (1963) work, also revealed no support for the view that the poor would be

\section{Table 1}

Dimension I: Attitudes, Values, and the Character Structure of Individuals

\begin{tabular}{lcccccc}
\hline & Poor & $\begin{array}{c}\text { Non- } \\
\text { poor }\end{array}$ & $\begin{array}{c}\text { Chi- } \\
\text { square }\end{array}$ & df & P & $(\mathrm{N})$ \\
\hline Powerlessness Scale (\% High)* & 62 & 72 & $2.6^{* * *}$ & 1 & $>.05$ & $(263)^{* * *}$ \\
Normlessness Scale (\% High)* & 33 & 53 & 11.1 & 2 & $<.05$ & $(268)$ \\
Social Isolation Scale (\% High)* & 21 & 10 & 8.1 & 2 & $<.05$ & $(265)$ \\
Self-esteem Scale (\% High)* & 67 & 62 & .6 & 1 & $>.05$ & $(266)$ \\
Psychological Pathology & & & & & & \\
$\quad$ (a) Behavior disorders among & & & & & & \\
$\quad$ 1st children (\% High) & 25 & 32 & .5 & 2 & $>.05$ & $(62)$ \\
$\quad$ (b) Mental Illness (\% none) & 91 & 94 & .6 & 1 & $>.05$ & $(271)$ \\
\hline
\end{tabular}

* These are subscales of Dwight G. Dean's Alienation scale. The scales were kindly supplied to us by the author (see Dean, 1961).

** The actual N's vary from item to item in the tables which follow, because "no answer" and "missing data" replies have been omitted. Also, in cases of items with screening questions (mainly those about work, children, and relatives) the N's are reduced to those in the sample for whom the questions were relevant.

**** Note that each line of percentages in this and subsequent summary tables is only one line, and thus one important response category, from a larger cross-tabulation table. Thus the chi-square statistics reflect what is occurring in the other categories of the cross-tabulation as well as what differentials exist in the listed category. 
more likely to rank low on self-esteem than the more affluent. While 67 percent of the poor ranked high on this scale, 62 percent of the non-poor ranked high. The association was in the direction opposite to a culture of poverty hypothesis.

The survey instrument contained two additional questions which could be used as indices of psychological pathology, a category of traits presumed to be more characteristic of the poor than the non-poor. For those families with children we found no significant association between income and a measure of behavioral disorders among first-born children. The same pattern was true for second-born and third-born children, although the number of non-poor families in this latter category was small. With regard to mental illness, almost all of the respondents reported that no one in their families presently or recently had mental illness. Of course, this is based on respondent reports and not on an actual examination. Nonetheless, there was no association between reported mental illness and income.

In addition, since this southwestern sample included a somewhat higher percentage of blacks over 60 years of age than in the city's population as a whole, we controlled for age and examined the relationships between income and our six attitudinal measures. We were particularly interested in the under-60 adult respondents, those most likely to correspond to Lewis' image of poor families. In no case was a prediction in line with poverty culture theory supported for the under60 group, when it was not for the sample as a whole (or vice versa).

Thus, only one of the six associations that we analyzed significantly supported culture of poverty hypotheses about this dimension. Indeed, with the exception of social isolation and mental illness, the associations were opposite to the direction predicted from the culture of poverty perspective.

\section{Dimension II: The Nature of the Family}

Another important dimension of the culture of poverty encompasses a variety of family variables. For the data to support Lewis' theses, the poor group should show distinctiveness in regard to consensual marriages, absence of childhood, female-centered families, authoritarianism, and verbal emphasis on family solidarity. Table 2 presents our data on the marital characteristics. Here we find little support for Lewis' argument that consensual or common-law marriages are widespread among the very poor. While the one case of a common-law marriage was to be found among the poor, this offers no support for viewing the typical married poor family in consensual terms. These data on marital status do offer support for one of Lewis' arguments, since a larger proportion of the families were "broken" in the poor group than in the non-poor group. Yet we suspect that the usual voluntary interpretation of this should be qualified, since a major reason for the high frequency of "broken" families was the death of a parent, a constraint indicating the involuntary character of much family dissolution.

Table 2

Dimension II: Marital Status

\begin{tabular}{lrr}
\hline $\begin{array}{l}\text { Marital } \\
\text { Status* }\end{array}$ & $\begin{array}{r}\text { Poor } \\
(\mathrm{N}=130)\end{array}$ & $\begin{array}{r}\text { Non-poor } \\
(\mathrm{N}=137)\end{array}$ \\
\hline Single & $8 \%$ & $12 \%$ \\
Common Law & $1 \%$ & $0 \%$ \\
Married & $31 \%$ & $53 \%$ \\
Separated & $11 \%$ & $14 \%$ \\
Divorced & $15 \%$ & $7 \%$ \\
Widowed & $35 \%$ & $14 \%$ \\
Totals & $101 \%$ & $100 \%$ \\
$\chi^{2}=26.6$, d.f. $=5, \mathrm{p}=<.05$ & \\
\hline
\end{tabular}

* Respondent replies to the marital status question were carefully checked against other data available to us. 
Table 3 presents information on a number of other family traits that Lewis accentuates. The measure of female-centered families lends support to Lewis' arguments, with 55 percent of the poor families being femaleheaded and 28 percent of the non-poor. Lewis also argues that the poor expect their children to be more independent at earlier ages, to have a shorter childhood than more affluent children. While the available questions were not as good as we would have preferred, our findings on childhood independence indicate that neither the poor nor the non-poor group seems to be pushing its children into adulthood. In no case were the differences statistically significant. In fact, with the exception of crossing streets alone, the differences are in the direction of the non-poor expecting more independence than the poor. The culture of poverty perspective emphasizes that the poor are distinguished by a strong disposition to "authoritarianism" in child-rearing practices. Looking at those families with children, one of our measures indicates support for this point of view; the other does not. First, the number of explicit behavioral rules that parents had for their children was analyzed by income; this revealed no difference between the two groups. Examination of the second measure-type of punishment for disobedience of a ten-year-old child-did show a significant difference between the two groups. Seventyseven percent of the poor respondents said they would use some form, mild or strong, of physical punishment, compared to 43 percent of the non-poor.

Table 3

Dimension II: Additional Measures on Family and Child-Rearing

\begin{tabular}{|c|c|c|c|c|c|c|}
\hline & $\begin{array}{l}\text { Poor } \\
\%\end{array}$ & $\begin{array}{l}\text { Non- } \\
\text { poor } \\
\% \\
\end{array}$ & $\chi^{2}$ & $\mathrm{df}$ & $\mathrm{p}$ & $(\mathrm{N})$ \\
\hline \multicolumn{7}{|l|}{ Female-centered families } \\
\hline$\%$ female household heads & 55 & 28 & 20.3 & 1 & $<.05$ & $(271)$ \\
\hline \multicolumn{7}{|l|}{ Absence of childhood } \\
\hline $\begin{array}{l}\text { Child should dress self by age } 10 \\
\text { Child should help around house }\end{array}$ & 94 & 95 & .02 & 1 & $>.05$ & $(89)$ \\
\hline $\begin{array}{l}\text { by age } 10 \\
\text { Child should cross street alone }\end{array}$ & 90 & 95 & .58 & 1 & $>.05$ & $(90)$ \\
\hline by age 10 & 29 & 15 & 2.4 & 1 & $>.05$ & $(90)$ \\
\hline $\begin{array}{l}\text { Child should take care of } \\
\text { younger children by age } 10\end{array}$ & 48 & 56 & .62 & 1 & $>.05$ & (91) \\
\hline \multicolumn{7}{|l|}{ Authoritarian child-rearing } \\
\hline $\begin{array}{l}\text { parents with } 3 \text { rules or more } \\
\text { parents using physical }\end{array}$ & 37 & 38 & .1 & 2 & $>.05$ & (87) \\
\hline punishment & 77 & 43 & 10.6 & 1 & $<.05$ & $(89)$ \\
\hline \multicolumn{7}{|l|}{$\begin{array}{l}\text { Emphasis on family solidarity } \\
\text { respondents spending } 6-7\end{array}$} \\
\hline $\begin{array}{l}\text { evenings home } \\
\text { respondents always do things }\end{array}$ & 83 & 70 & 4.1 & 2 & $>.05$ & $(166)$ \\
\hline as a family & 68 & 65 & 2.3 & 2 & $>.05$ & (160) \\
\hline
\end{tabular}


In addition, according to a culture of poverty hypothesis, one should find a distinctive emphasis on family solidarity among the poor. These data revealed no statistically significant differences between the two income groups on several measures of family interaction: in regard to spending evenings at home with the family and in regard to doing things as a family. In the former case, however, the direction of the difference was in the direction Lewis would have predicted.

Examining each relationship for our sample split into a younger and an older age group revealed no change in the directions or the significance of the basic associations for the below-60 group, with regard to marital status and the two measures of family solidarity. We did not control for age with regard to the indices of absence of childhood and authoritarianism, since all but a handful of the heads of household of families with children were below the age of 60. With regard to Lewis' predictions about family life we found limited support in these data. While the data indicate significant differences in family composition between the poor and the non-poor, the measures related to absence of childhood and family solidarity suggest no significant differences between the poor and the non-poor groups. And only one of two measures related to child-rearing showed support for Lewis' generalizations.

\section{Dimension III: The Nature of the Slum Community}

The traits Lewis itemizes under this rubric have a heterogeneous character, since Lewis includes physical housing conditions and gregariousness under the same dimen- sion. For the data to lend strong support to the culture of poverty perspective, they should show that the poor group is in significantly worse shape than the non-poor in regard to housing conditions and social participation beyond the family, and the poor should be generally more "gregarious" with regard to primary social ties.

As can be seen in Table 4, our data indicate that the poor group is more distinctive in regard to this dimension than in regard to the two previous dimensions. Cross-classifying the housing measures with income revealed significant differences with regard to measures of housing quality and with regard to crowding (larger families, but housing units of roughly the same size). These differences are in line with what Lewis would predict.

The measure of neighborhood participation relates to respondents' perception of help patterns among neighbors, but the association was not as predicted. Our two measures of organizational (secondary) participation indicate no significant association between income and church attendance and between income and contact with the major local civil rights organization. And our measures of gregariousness other than neighboring, relating to kinship interaction, are not in line with the culture of poverty perspective. The poor and non-poor groups were not significantly different with regard to kinship interaction.

When age is controlled and the younger group examined separately, the significance of the basic associations (and the direction of the significant associations) is not affected, with two exceptions. In the case of the measures of neighborliness and number of dependents, the nonsignificant associations with income become significant when the below60 age group is examined separately. 


\section{Dimension IV:}

\section{The Relationship between the Culture and the Larger Society}

Under this rubric culture of poverty theorists detail a lengthy list of culture traits which relate to the "integration of the poor in the major institutions of the larger society" (Lewis, 1965:xli). In Table 5 we have roughly grouped our measures into five areas that Lewis emphasized in regard to the integration of the poor into the larger society: segregation, discrimination, economic resources, political action, knowledge and use of public facilities, and attitudes toward dominant groups and institutions. Looking at specific measures relating to segregation and discrimination, we see that each of these items of- fers weak to strong directional support for the predictions, although only the association relating to segregated work settings attains statistical significance. The six indices of lack of economic and educational resources indicate the seriously disadvantaged pattern that the poverty culture perspective suggests. The poor were significantly more likely than the non-poor to be in unskilled jobs, to have unemployment in the family, to have serious money problems, to have second-hand furniture, and to have less in the way of education. The same was true for the one measure of political action, voting in the last presidential election, although the attitudinal item relating to Negroes organizing politically showed no differences between the two income groups.

Table 4

Dimension III: Housing Conditions and Other Factors

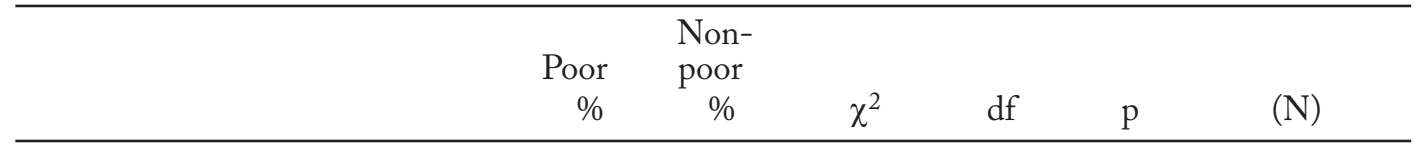

Housing Conditions

Deteriorating and dilapidated houses*

Cleanliness of yards* (\% cluttered)

Partially furnished*

Poor to very poor furnishings*

58
76

Lighting of streets good**

76

46

46
7

\section{3}

$2<.05$

48

34.8

$3<.05$

Crowding

1-2 bedrooms only

3 or more dependents

$\begin{array}{rrr}.1 & 2 & >.05 \\ 2.6 & 1 & >.05\end{array}$

Gregariousness

visit relatives $7 /$ week

received help-housework —sickness

$\begin{array}{rll}2.6 & 3 & >.05 \\ .8 & 1 & >.05 \\ .4 & 1 & >.05\end{array}$

Organizational Activity beyond

kinship level

people in neighborhood willing to help attend church 2-4 times month have had contact with NAACP

$\begin{array}{rrrrr}80 & 88 & 2.6 & 1 & >.05 \\ 72 & 79 & 2.9 & 2 & >.05 \\ 4 & 8 & 1.8 & 1 & >.05\end{array}$

\footnotetext{
* Based on interviewer assessments.

** Based on respondents' assessments.
} 
Table 5

Dimension IV: Discrimination, Economic Resources and Other Factors

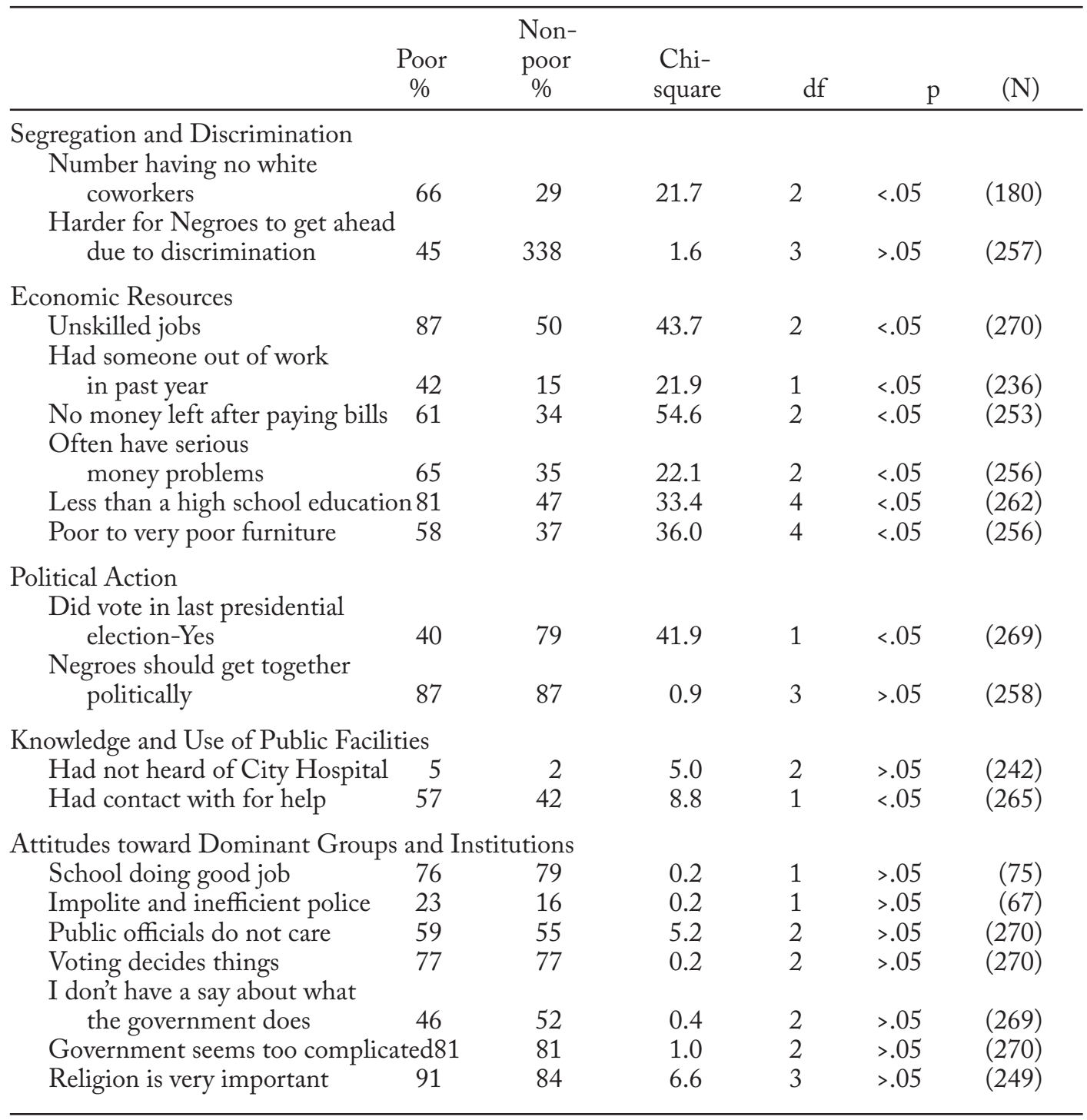

The measures related to use of public facilities indicated that only small minorities in either group had not heard of the major public hospital. In fact, on one of the two items under this heading the directional difference is opposite to the lack of contact one might predict from a poverty culture perspective; the poor were more likely than the non-poor to have used the city hospital.
Our measures of attitudes toward dominant groups and institutions offered no significant support for Lewis' contentions about the distinctive suspicion of institutions, the fear, the apathy of those caught up in a culture of poverty. The poor were not significantly more likely than the non-poor to be critical of the jobs the schools and the police were doing, to feel public officials don't care 
what they think, to be critical of voting or the government, or to downgrade religion in importance. This is not to say that there was not substantial criticism of dominant groups and institutions among these black Americans. Indeed, there was substantial criticism, but it did not vary by socioeconomic status.

When controls were applied, neither direction of differences nor statistical significance was altered for the under-60 groups, with two exceptions. Among the under-60 respondents, the poor were significantly less likely than the non-poor to have heard of the city hospital, although most had heard of it. And the poor were slightly more likely than the non-poor to feel voting decides things, but the association in the younger age group was not statistically significant.

\section{Summary and Conclusion}

In this paper we have examined the four major dimensions or aspects of the culture of poverty distinguished by Oscar Lewis in La Vida (1965). More specifically, we have grouped indicators drawn from interviews with a large sample of black Americans in a major renewal area so that they relate to the four basic dimensions of the culture of poverty which Lewis emphasized.

Let us briefly summarize the pattern of our findings. Under the category of general attitudes, values, and the character structure of individuals, we examined five broad traits and found statistically significant support for a culture of poverty hypothesis in only one case, that of social isolation attitudes. In one other case the association was statistically significant in the direction opposite that which would be predicted by culture of poverty theory. Thus, the data relevant to this dimension provide little support for Lewis' perspective. Under the category of the na- ture of the family, we examined indices relevant to four basic traits and found consistent support for Lewis' perspective in only one case, that of family structure. We also found support for a culture of poverty hypothesis on one of our two measures of "authoritarian" child-rearing. Thus the data relevant to this dimension provide consistent support for only one of the four basic traits asserted to distinguish the poor from the nonpoor. Under the rubric of the relationship of the subculture to the larger society, we again examined five broad traits and found some support for culture of poverty assertions in regard to segregation, political action, and lack of economic resources. However, in the first two cases not all items supported Lewis' perspective.

Taking all the broad traits in all dimensions together, we can report some support for Lewis' assertions in less than half of the cases; and in several of these instances some indices did not corroborate the predictions. With regard to about 60 percent of the fundamental poverty culture traits, we found no support for a perspective distinguishing the poor from non-poor in their way of life. Particularly striking, moreover, is the character of the majority of the traits where we did find statistically significant support for Oscar Lewis' contentions. In four of these cases the traits have to do more with what Valentine (1968:115) called the "externally imposed conditions or unavoidable matters of situational expediency, rather than cultural creations internal to the sub-society in question." These four cases are housing conditions, crowding, segregation, and the lack of economic resources. From this perspective, these seem to be alternative measures of, or indicators of, low-income status or poverty. Thus we are inclined to agree with Valentine that these can better be viewed as conditions of poverty than as solutions to 
poverty arising out of the cultural innovations of poor people.

Indeed, we would argue further that our findings on these four traits appear to offer more support for a "situational" interpretation of poverty than for the culture of poverty, perspective. By a "situational" interpretation we mean that the poor are confronted by such situational factors as low-income, lowpaying jobs, and inadequate housing in the main through no fault of their own. "That is, these conditions are phenomena of the environment in which the lower class lives, determined not so much by the behaviors and values of the poor as by the structure of the total social system" (Valentine, 1968:116). While we are inclined toward this model rather than the one outlined by Oscar Lewis, we do not here wish to contend that our evidence conclusively supports such an alternative model. However, we do wish to suggest that half of the traits for which we found strong support could as well be interpreted in situational terms rather than culture of poverty terms. At the very least, both models deserve testing in future analyses.

Thus these findings, while limited to one large black sample in a southwestern city, do not offer consistent, across-the-board support for a culture of poverty perspective, one which stresses that the very poor in all countries, and in all ethnic groups, are distinctively different in their designs for living from those who are more affuent. This point seems rather critical from the point of view of public policy, since the culture of poverty perspective now appears to be the dominant one at the level of federal government analysis and policymaking. We have already noted the great emphasis given to the attitudes and behavioral patterns of the poor in government publications such as Chilman's Growing Up Poor (1966). Surely it is unfortunate that theories such as that articulated by Os- car Lewis come to be accepted as fact before systematic empirical analysis of the attitudes, behaviors, and actions of the poor and nonpoor has been carried out. While it has become conventional to call for additional research at the end of social science research papers, we hope that some will listen when we assert that, given the present state of social science research on the culture of poverty, no one should predicate policy decisions affecting low-income Americans, black or white, on such a theory. To do so is again to trust in unproven conventional wisdom which is increasingly becoming questionable.

\section{References}

Chilman, Catherine S.

1966 Growing Up Poor. Washington, D.C.: U.S. Government Printing Office.

Dean, Dwight G.

1961 "Alienation: its meaning and measurement." American Sociological Review 26 (October): 754-758.

Hagood, Margaret J., and Daniel O. Price

1952 Statistics for Sociologists. New York: Holt, Rinehart, and Winston.

Holland, Barbara Coward

1971 A study of Oscar Lewis' Culture of Poverty. Austin: University of Texas. M.A. Thesis.

Irelan, Lola M., Oliver C. Moles, and Robert O'Shea

1969 "Ethnicity, poverty, and selected attitudes: a test of the "Culture of Poverty' hypothesis.” Social Forces 47 (June): 405-413.

Johnson, Norman J., and Peggy R. Sanday

1971 "Subcultural variations in an urban poor population.” American Anthropologist 73 (February): 128-143.

Leeds, Anthony

1971 "The concept of the 'Culture of Poverty': conceptual, logical, and empiri- 
cal problems, with perspectives from Brazil and Peru." Pp. 226-284 in E1eanor B. Leacock (ed.), The Culture of Poverty: A Critique. New York: Simon and Schuster.

Lewis, Oscar

1964 “The culture of poverty." In John J. Tepaske and Sydney N. Fisher (eds.), Explosive Forces in Latin America. Columbus: Ohio State University Press.

1965 La Vida. New York: Random House.

Roach, Jack L., and Orville R. Gursslin

1967 "An evaluation of the concept 'Culture of Poverty.' " Social Forces 45 (March): 383-392.

Rodman, Hyman

1968 "The lower class value stretch." Pp. 270-285 in Louis A. Ferman et al. (eds.), Poverty in America. Ann Arbor: The University of Michigan Press.

Rosenberg, Morris

1963 "Parental self-interest and children's self-conceptions." Sociometry 26 (March): 35-49.

Schneiderman, Leonard

1964 "Value orientation preferences of chronic relief recipients." Social Work 9 (July): 13-18.

Valentine, Charles A.

1968 Culture and Poverty. Chicago: The University of Chicago Press.

1971 “The 'Culture of Poverty': its scientific significance and its implications for action." Pp. 193-223 in Eleanor B. Leacock (ed.), The Culture of Poverty: A Critique. New York: Simon and Schuster. 